\title{
Consumer-generated reviews: time for closer scrutiny?
}

Nwanneka Ezechukwu*

School of Law, Birmingham City University, England

*Author email: nwanneka.ezechukwu@bcu.ac.uk

\section{Refereed Article (Accepted version)}

ABSTRACT. This article focuses on consumer-generated reviews (CGRs) which are an increasingly influential source of consumer information. In particular, the article highlights specific problems associated with CGRs, which questions their role as a reliable information source. Flowing from this, the article calls for closer regulatory scrutiny of review platforms who play an important intermediary role in facilitating the provision of CGRs. To this end, the article considers possible regulatory responses in the European Union which may address some of the issues highlighted.

Keywords: consumer law; consumer-generated reviews; consumer information; review platforms; online platforms; platform operators; duty of care

\section{INTRODUCTION}

Under classical economic theory, consumers play an important role in maintaining market discipline because they can use their transactional decisions to ensure that suppliers act in their best interest. ${ }^{1}$ Optimal consumer decision-making is, however, dependent on access to complete and accurate information on the price, characteristics and quality of a commodity (and its substitutes) as well as the terms on which it is sold. ${ }^{2}$ In reality, obtaining information is costly and in some cases, impossible for consumers. ${ }^{3}$ The consequence is that consumers and suppliers often have an uneven amount of information which places them in unequal bargaining positions. ${ }^{4}$

* A version of this article was first presented at the Society of Legal Scholars Conference (UClan, Preston, 2019). My sincere thanks to Prof. Peter Cartwright and Prof Richard Hyde and the anonymous reviewers for their helpful comments on earlier drafts. All errors remain mine.

${ }^{1}$ G Howells, S Weatherill, Consumer Protection Law (Aldershot: Ashgate, 2nd edn, 2005) 32.

${ }^{2}$ ME Budnitz, M Rojo and J Marlowe 'Deceptive Claims for prepaid telephone cards and the need for regulation' (2006) 19 Loyola Consum.L.Rev 1,4.

${ }^{3}$ It is impossible to acquire complete information for products purchased on a "credence basis" because it may be impossible to access their value even after use or because their value may only become apparent with the passing of time: M Donnelly 'The financial services ombudsman: asking the existential question' (2012) 35 DULJ 232, 234.

${ }^{4}$ I Ramsay, Consumer Law and Policy (, Oxford: Hart Publishing, 3rd edn, 2012) 41 
Accordingly, regulatory intervention in consumer markets is frequently justified on the need to reduce information gaps to allow consumers make well-informed decisions reflecting their preferences. ${ }^{5}$ To this end, legislators and regulators deploy techniques aimed at improving consumer access to information. A commonly used technique is mandatory disclosure, which requires that businesses supply specific information to consumers. ${ }^{6}$ Mandatory disclosure aims to give disclosees the information required to make better decisions and to keep disclosers from abusing their superior position. ${ }^{7}$

The use of mandatory disclosure has been criticised because it is thought to rest on "false assumptions about how people live, think, and make decisions." ${ }^{8}$ Mandatory disclosure relies on the neo-classical assumption that consumers are rational and are the best judges of their interests who maximise their utility with the limited resources available. ${ }^{9}$ This assumption has been questioned by behavioural research which suggests that even when consumers have access to information, there is a tendency not to process such information correctly for several reasons, including the susceptibility to behavioural biases. ${ }^{10}$

Ben-Shahar and Schneider provide a well-articulated criticism of mandatory disclosure in their book More Than You Wanted To Know. ${ }^{11}$ Amongst other things, They assert that-

\footnotetext{
${ }^{5}$ G Howells, 'The potential and limits of consumer empowerment by information' (2005) 32 J Law \& Soc'y 349, 355.

6 P Latimer and P Maume, Promoting Information in the Marketplace for Financial Services (Switzerland: Springer, 2014) 28.

7 O Ben-Shahar and C Schneider, 'The failure of mandated disclosure' (2011) 159 UPLR. 647, 649.

${ }^{8}$ Ibid, p 651.

${ }^{9}$ I Ramsay, 'Rationales for intervention in the consumer marketplace' (London, Office of Fair Trading 1984) cited in Ramsay, above n 4, p 47.

${ }^{10}$ See, for example, HA Simon, ‘A behavioural model of rational choice' (1955) 69(1) The Quarterly J of Econ. 99; A Tversky \& D Kahneman, 'Prospect theory: an analysis of decision under risk' (1979) 47(2) Econometrica 263; CR Sunstein, RH Thaler, Nudge: Improving Decisions About Health, Wealth and Happiness (New Haven: Yale University Press 2008).

${ }^{11}$ O Ben-Shahar, CE Schneider More than You Wanted to Know: The Failure of Mandated Disclosure (Princeton: Princeton University Press 2014)
} 
Faced with unfamiliar and complex decisions that disclosures are intended to inform, people don't want to be educated, don't want spreadsheets and don't want scrolls. They want advice. ${ }^{12}$

They highlight that many markets provide advice in the form of 'ratings, rankings, scores, grades, labels, warnings and reviews' and that such advice often does better than disclosures in helping consumers make unfamiliar and complex decisions. ${ }^{13}$ Supporting their assertion, growing evidence suggests that consumers increasingly rely on one type of advice consumer-generated reviews (CGRs) - when making transactional decisions. ${ }^{14}$ This trend is fuelled by the growth of electronic commerce and online platforms which allow consumers to share their evaluation of products.

Since consumers rely on CGRs in decision-making, this alternative information stream invites closer scrutiny. This article has two goals. First, it will highlight specific problems which question the reliability of CGRs as a source of consumer information. ${ }^{15}$ Second, it considers regulatory responses which may address some of the problems highlighted. To this end, this article is structured as follows: Following this introduction, section one considers the growing emergence and merits of CGRs. Section two discusses certain problems associated with CGRs, while section three considers the appropriate regulatory responses to these problems. Conclusions are then drawn in section four.

\section{CONSUMER-GENERATED REVIEWS: AN ALTERNATIVE?}

\footnotetext{
${ }^{12}$ Ibid, p 185 (emphasis added).

${ }^{13}$ Ibid, pp 185, 190.

${ }^{14}$ WW Moe and M Trusov 'Measuring the value of social dynamics in online product ratings forums' (2011) 48 JMR 444.

${ }^{15}$ This article focuses on reviews directly generated from consumers. Reviews from third-party expert intermediaries are not within the scope of the discussion.
} 
Consumer-to-consumer information sharing is not novel because word-of-mouth information exchange amongst peers is an ancient communication mechanism. ${ }^{16}$ While word-of-mouth exchanges had a limited reach, the internet provides a low-cost channel for disseminating information on an unprecedented scale. ${ }^{17}$ With the rise of online transactions, it has become the norm for retail websites to incorporate forums enabling consumers to discuss their experiences of using products and dealing with suppliers. ${ }^{18}$ There are also independent websites solely dedicated to aggregating consumer reviews. ${ }^{19}$ These forums are usually free to access and primarily serve to facilitate information exchange amongst consumers. ${ }^{20}$ CGRs posted on these forums may come in the form of open-ended textual information on a product's perceived quality. ${ }^{21}$ They may also come in the form of ratings where a consumer's evaluation of a product is represented by a specified number on a scale or by the use of stars. ${ }^{22}$ Many online platforms combine both. While ratings give consumers a quick indication of a product's popularity, open-ended textual information provides specific details reflecting each reviewer's experience.

CGRs serve two functions. First, they act as informants because they provide consumers with additional information derived from other consumers' experiences. ${ }^{23}$ Second, they act as recommenders since they provide positive or negative signals about a product's popularity,

\footnotetext{
${ }^{16} \mathrm{C}$ Dellarocas 'The digitization of word of mouth: promise and challenges of online feedback mechanisms’ (2003). 49 Manag. Sci. 1407, 1409.

17 Ibid.

18 J Schneider '10 Tactics for launching a product using social media' (2015) available at https://hbr.org/2015/04/10-tactics-for-launching-a-product-using-social-media

${ }^{19}$ E.g. Trustpilot.

${ }^{20}$ WW Moe and M Trusov, The value of social dynamics in online product ratings forums (2011) 48 JMR 444, 444.

${ }^{21}$ SP Eslami, MGhasemaghaei and K Hassanein 'Which online reviews do consumers find most helpful? A multi-method investigation' (2018) 118 DSS 32, 32.

${ }^{22} \mathrm{G}$ Lackermair, D Kailer and K Kanmaz 'Importance of online product reviews from a consumer's perspective' (2013) 1(1) Advances in Economics and Business 1, 1.

${ }^{23}$ D Park and I Han 'Integrating conflicting reviews: attributional hypotheses of consumer response to information uncertainty depending on prior brand attitude' (2008) available at http://citeseerx.ist.psu.edu/viewdoc/download?doi=10.1.1.466.3727\&rep=rep1\&type=pdf
} 
which reflects the overall positive reviews that the product generates. ${ }^{24}$ These functions place CGRs as one of the most influential non-marketer sources of product information. ${ }^{25}$ Evidence suggests that CGRs affect the decision-making and purchasing behaviour of consumers. ${ }^{26}$ For instance, research carried out by Review Trackers reveals that 63.6 per cent of consumers are likely to check online reviews on Google before transacting with a business. ${ }^{27} 94$ per cent admit that a negative online review has convinced them to avoid a business. ${ }^{28}$

The influence of CGRs on consumer decision-making can be explained by certain benefits that they provide, which are discussed below.

\section{a) Reduces search costs}

To make optimal decisions, consumers must gather and process sufficient information on products as well as their substitutes. This process is costly in terms of money, time and effort. ${ }^{29}$ If consumers believe that the cost of searching for information outweighs the benefit, they may settle for products that do not represent their preference or the best bargain that they could have obtained. $^{30}$

The internet contributes to reducing search costs by facilitating easy and timely access to CGRs at little to no cost. ${ }^{31}$ Consumers can access thousands of reviews on their personal computers or mobile devices which enables them to compare products and their prices. ${ }^{32}$ One

\footnotetext{
24 Ibid.

${ }^{25}$ SA Gottschalk and A Mafael 'Cutting through the online review jungle — investigating selective eWom processing' (2017) 37 JIM 89, 91.

${ }^{26}$ Moe and Trusov, above n 20 p 444.

${ }^{27} \mathrm{https}$ ://www.reviewtrackers.com/reports/online-reviews-survey/

28 Ibid.

${ }^{29}$ L Garrod, M Hviid and G Loomes et al 'Competition remedies in consumer markets' (2009) 21 LCLR $439,442$.

${ }^{30} \mathrm{JH}$ Russell 'Misbehavioral law and economics' (2018) 51 UMJLR 549, 557.

${ }^{31}$ DA Friedman 'Do we need help using yelp: regulating advertising on mediated reputation systems' (2017) 51 UMJLR 97, 126.

32 S Colin 'Innovation and the Online Consumer' (2004) 26 Law \& Policy 477, 479.
} 
empirical study suggests that CGRs can reduce search time by about $25 \%{ }^{33}$ which is valuable to consumers seeking relevant and timely information. ${ }^{34}$

\section{b) Reduces uncertainty}

Consumers face uncertainties online because parties are not physically transacting with each other and because many transactions are one-off events. Consumers' uncertainty is also fuelled by the inability to verify the identity of suppliers and the attributes/quality of products before purchase. ${ }^{35}$ These uncertainties result from the lack of perfect information. ${ }^{36}$

To overcome uncertainties, consumers read reviews to obtain information. ${ }^{37}$ Information acquired gives consumers some confidence since CGRs set clearer expectations of a product's performance. In comparison to information provided by businesses, consumers also trust and place a higher value in the opinion of their peers. ${ }^{38}$ This may be because of the perceived noncommercial motives of their peers. ${ }^{39}$ CGRs also emphasise information that consumers may have ignored or thought less-significant. ${ }^{40}$ For instance, reviews may highlight the difficulty in contacting a supplier to secure refunds for defective products - a less salient issue that consumers may not have considered initially.

\section{c) User-oriented}

Business-to-consumer information is often criticised as complex and product-oriented because it focuses on describing product attributes and performance in terms of technical

\footnotetext{
${ }^{33} \mathrm{~N}$ Amblee, R Ullah and W Kim 'Do product reviews really reduce search costs? available at https://www.researchgate.net/publication/317083455 Do_Product Reviews_Really_Reduce_Search_Co sts accessed 25th July 2019 p 4.

${ }^{34}$ Friedman, above n 31, p 130.

35 S Chatterjee and P Datta 'Examining Inefficiencies and consumer uncertainties in e-commerce' (2008) 22 Communications of the Association for Information Systems 525, 528.

${ }^{36}$ Ibid, p 530.

${ }^{37}$ D Weathers, SD Swain and V Grover 'Can online product reviews be more helpful? Examining characteristics of information content by product type’ (2015) 79 DSS 12, 12.

${ }^{38}$ Friedman, above n 31, 126.

${ }^{39}$ LM Willemsen, PC Neijens, et al 'Highly recommended! the content characteristics and perceived usefulness of online consumer reviews' (2011) JCMC 19.

${ }^{40}$ Ibid, p 15.
} 
specifications. ${ }^{41}$ It is also usually voluminous, making it difficult for consumers to understand. Consequently, regulators often require that business-to-consumer disclosures are simplified. Simplification may involve drafting disclosures in simple language or streamlining the presentation of disclosed content. ${ }^{42}$ However, Ben-Shahar and Schneider explain that 'simplifying [disclosures] fail because the complex isn't simple and can't easily be made so."43 Simply put, it is challenging to present complicated information in written language that most people understand. ${ }^{44}$

Because CGRs are written from a consumer perspective, in comparison to disclosures, they may convey information in a less complicated manner. ${ }^{45}$ Being expressed in more relatable language, consumers may find them easier to understand. They will not be as lengthy as disclosures and will provide information that is based on user experience.

\section{d) Good Mechanism for Disciplining Firms:}

The internet provides a relatively cheap medium which allows consumers to reveal the actions of suppliers and to attract other consumers' attention in the process. ${ }^{46}$ Suppliers care about CGRs because they can affect future profits. ${ }^{47}$ If many CGRs express dissatisfaction with a firm's products, it creates a negative perception of the product and the firm's reputation. Since perception can impact sales, suppliers have an incentive to behave appropriately. ${ }^{48}$

Some commentators believe that the potential to discipline firms can impact the regulation of contracts terms. Taylor argues that if a firm's reputation is attacked because

\footnotetext{
${ }^{41}$ Park and Han, above n 34.

42 O Ben-Shahar and A Chilton 'Simplification of privacy disclosures: an experimental test' (2016) 45(2) JLS 541, 542-543.

${ }^{43}$ Ben-Shahar \& Schneider, above n 7, p 123.

${ }^{44}$ CE Schneider and MA Hall 'The patient life: can consumers direct health care' (2009) 35 AM JL \& Med 7, 42.

${ }^{45}$ Park and Han, above n 23, p 1.

${ }^{46}$ MN Helveston 'Regulating digital markets' (2016) 13 NYU JL \& Bus 33, 49

${ }^{47}$ Dellarocas, above n 16, p 1410.

${ }^{48}$ Ibid, p 1408.
} 
consumers criticise their contract terms, the firm may be motivated to change unfavourable terms ${ }^{49}$ Echoing this, Becher and Zarsky contend that the information flow between consumers will force suppliers to remove unfair terms, especially where a possibility exists that consumers will refrain from contracting with them. ${ }^{50}$ While this may be true in some cases, ${ }^{51}$ discussions in section two will show that this is an optimistic view because it rests on the assumption that many consumers will be motivated enough to read contract terms and to write reviews assessing them.

\section{PROBLEMS WITH CONSUMER-GENERATED REVIEWS}

The integrity of available information affects the quality of consumer decision-making. While CGRs contribute to reducing information gaps, certain concerns question their role as a reliable source of consumer information. These concerns are considered below.

\section{a) Bias}

CGRs can leave consumers with misleading, inaccurate or false information because a product's aggregated reviews may not reflect the unbiased opinion of other consumers. ${ }^{52}$ Information contained in CGRs may be biased for several reasons discussed below.

\section{i. FAKE REVIEWS}

Since CGRs can impact sales, businesses are incentivised to ensure that reviews remain positive. ${ }^{53}$ Consequently, they may commission fake reviews by paying for them or by planting

\footnotetext{
${ }^{49}$ RB Taylor 'Consumer-driven changes to online form contracts' (2011) 67 N.Y.U. Ann. Surv. Am. L. 371,378 .

${ }^{50}$ SI Becher and TZ Zarsky 'E-contract doctrine 2.0: standard form contracting in the age of online user participation' (2008) 14 Mich. Telecomm. \& Tech. L. Rev. 303.

${ }^{51}$ In 2011, a campaign led by a customer forced the Bank of America to redefine its debit card fee structure. Available at https://www.businessinsider.com/molly-katchpole-petition-leads-ordinary-mansfight-against-bank-of-america-debit-fees-2011-10?r=US\&IR=T

${ }^{52}$ J Malbon 'Taking fake online consumer reviews seriously' (2013) 36 JCP 149.

${ }^{53} \mathrm{X} \mathrm{Li}$ and LM Hitt 'Self-Selection and information role of online product reviews' (2007) available at https://faculty.wharton.upenn.edu/wp-content/uploads/2012/04/Self-selection.pdf p 5.
} 
them on platforms using automated software programs (bots) ${ }^{54}$ Enforcement cases highlight this problem. In 2019, the US Federal Trade Commission (FTC) announced its first case challenging a marketer's use of fake paid reviews. ${ }^{55}$ The defendants allegedly paid a third-party website to create and post Amazon reviews of its weight-loss pill. These sham reviews helped the product attain a 5-star rating on Amazon. The court order settling the FTC's complaint, amongst other things, required that notices detailing the FTC's complaints be emailed to consumers who had purchased the product.

Similarly, in 2014, Bell Canada's employees were encouraged to post positive reviews of the company's apps on the iTunes and Google Play Store. ${ }^{56}$ These reviews were posted without the reviewers disclosing that they were Bell Canada employees. Canada's Competition Bureau determined that the reviews 'created the general impression that they were made by independent and impartial consumers and temporarily affected the overall star rating for the apps. ${ }^{57}$ The Bureau required that Bell Canada enhance its compliance program to ensure that employees would not review products. ${ }^{58}$

The practices highlighted in these cases can undermine the reliability of the information contained in CGRs. ${ }^{59}$ Even where consumers are cautious, they are cognitively ill-equipped to identify fake reviews because humans have a truth bias. This means that they are likely to

\footnotetext{
${ }^{54}$ LM Ponte 'Mad men posing as ordinary consumers: the essential role of self-regulation and industry ethics on decreasing deceptive online consumer ratings and reviews' (2013) 12 J. Marshall Rev Intell Prop L 462, 481.

55 https://www.ftc.gov/news-events/press-releases/2019/02/ftc-brings-first-case-challenging-fakepaid-reviews-independent

${ }^{56} \mathrm{https://www.competitionbureau.gc.ca/eic/site/cb-bc.nsf/eng/03992.html}$

${ }^{57}$ Ibid.

${ }^{58}$ Ibid.

${ }^{59}$ They also raise wider competition concerns because they put honest competitors who do not adopt similar practices at a disadvantage. Y Procaccia and A Harel 'On the optimal regulation of unread contracts' (2012) 8(1) Rev Law \& Economics 59-89, 76.
} 
believe information reported as true rather than false. ${ }^{60}$ This raises problems because decisions influenced by sham reviews may not be optimal.

Many CGRs are written anonymously, and the inability to verify a reviewer's identity is associated with the higher possibility of fake reviews. Platforms like Amazon adopt mechanisms which aim to partly resolve this. For instance, verified purchasers have an indicative badge on their reviews. However, Amazon also permits reviews written by unverified purchasers. This means that reviews written by unverified purchasers, who may or may not be fake reviewers, can influence a product's overall rating.

\section{ii. CONTRIBUtOR INTEGRITY AND COMPETENCE}

Genuine reviews may be biased due to the reviewer's experience or motivation. Contributor integrity problems exist in online forums because consumers cannot verify a reviewer's knowledge or reliability. ${ }^{61}$ This is significant because such interactions are usually nonrecurring. ${ }^{62}$

A reviewer's knowledge and experience affects the quality of information that they provide. For instance, an experienced long-term user of a product may provide better information than a first-time user. Thus, if the reviewer is incompetent or inexperienced, then the advice they provide may be inaccurate and misleading. ${ }^{63}$ It is usually difficult or near impossible for consumers to identify which reviews have been written by experienced or knowledgeable peers. Although some reviewers leave cues indicating their experience, these are not easily verifiable. ${ }^{64}$

\footnotetext{
${ }^{60} \mathrm{CNH}$ Street and A Kingstone 'Aligning spinoza with descartes: an informed cartesian account of the truth bias' (2017) 108 BJP 453, 453.

${ }^{61}$ Commonly described as an accreditation problem: Becher and Zarsky, above n 50, p 333.

${ }^{62}$ Ibid.

${ }^{63}$ Ibid, p 334.

${ }^{64}$ Cues could include statements like 'I have used this product for five years' which indicate experience and knowledge.
} 
Moreover, reviewers do not have strong incentives to post truthful information. This directly contrasts with firms required to provide mandatory disclosures. Such firms will face regulatory sanctions and lawsuits if they fail to provide truthful information. ${ }^{65}$ Should a consumer's transactional decision be induced by false or misleading disclosures, laws like the UK's Consumer Protection from Unfair Trading Regulations (CPUTRs) ${ }^{66}$ will protect them. However, if an anonymous review induces a transaction, in the absence of a direct contractual link with the reviewer, the consumer may have no remedy. ${ }^{67}$ Anonymous reviewers will also not qualify as traders for the CPUTRs to apply. ${ }^{68}$

Contributor integrity problems can also be linked to the fact that when writing reviews, consumers may be motivated by factors other than the objective evaluation of a product. For instance, evidence suggests that social influence bias affects how consumers write reviews. ${ }^{69}$ Consumers do not write reviews in isolation. They are often exposed to numerous information signals within the review platforms which affect the objective assessment of a product. ${ }^{70}$ Schlosser, for instance, finds that consumers may negatively adjust their review after reading a negative review. ${ }^{71}$ She theorizes that this may be because consumers seek to differentiate their reviews and negative reviews stand out because they are perceived as more intelligent. ${ }^{72}$ Confirming the existence of social influence bias, another study shows that consumers who

\footnotetext{
${ }^{65}$ The aggrieved consumer may also sue for breach of contract or misrepresentation.

${ }^{66}$ (2008); Regulation 5 prohibits misleading actions which could involve the use of false information which causes or is likely to cause the average consumer to take a transactional decision that he would not otherwise have taken.

${ }^{67}$ The aggrieved consumer cannot also sue under tort law (negligent misstatements) as there needs to be a special relationship which exists between the parties that justifies the existence of a duty of care.

${ }^{68}$ Regulation 2(1) defines a trader as "any person who in relation to a commercial practice is acting for purposes relating to his business, and anyone acting in the name of or on behalf of a trader."

${ }^{69} \mathrm{G}$ Askalidis, SJ Kim and EC Malthouse 'Understanding and overcoming biases in online review systems' (2017) 97 DSS 23, 25.

${ }^{70} \mathrm{~S}$ Cicognani, P Figini and M Magnani 'Social influence bias in online ratings: a field experiment' (2016) available at https://pdfs.semanticscholar.org/d5a3/9b7d1 fbfbdcd61dfc575fe 71cc9fd2b54bf0.pdf p 4.

${ }^{71}$ A Schlosser 'Posting versus lurking: communicating in a multiple audience context' (2005) 32 (2) J. Consum. Res, 260-65 cited in Moe and Trusov, above n 31, p 446.

${ }^{72}$ Ibid.
} 
received email invitations and who could not see reviews written by their peers consistently provided higher ratings when compared to self-motivated reviews provided by those who had access to other reviews. ${ }^{73}$

The signals as to product quality provided by aggregated CGRs may also be skewed because many consumers self-select to provide reviews. Hu et al point out that reviews are often written by consumers who are either extremely satisfied or dissatisfied. ${ }^{74}$ The averagely satisfied consumers who may represent the majority are less likely to write reviews. ${ }^{75}$ Hence, the information provided in CGRs may reflect only the views of a vocal minority. Such information will be biased since it is written by a non- representative sample of consumers. ${ }^{76}$

\section{iii. Platform MANipUlation}

Sometimes, review platforms (RPs) may not be neutral, and this can affect the quality of the information exchanged. Bias on such platforms may be traced to the RPs' business structure. RPs may be grouped as 'stand-alone' platforms or 'supportive' platforms. ${ }^{77}$ Stand-alone platforms are solely designed to allow consumers to share reviews. Such platforms often rely on advertising and subscription revenue. ${ }^{78}$ Examples include Trustpilot and Yelp. Supportive platforms also allow the sharing of reviews, but they are supplementary to a larger forum for facilitating transactions. ${ }^{79}$ An example would be Amazon.

Friedman explains that because stand-alone platforms need to generate revenue through advertising, promotions, and sales-commission, they are subject to tensions arising from potential conflicts of interest. ${ }^{80}$ This is because they seek to provide a neutral platform for

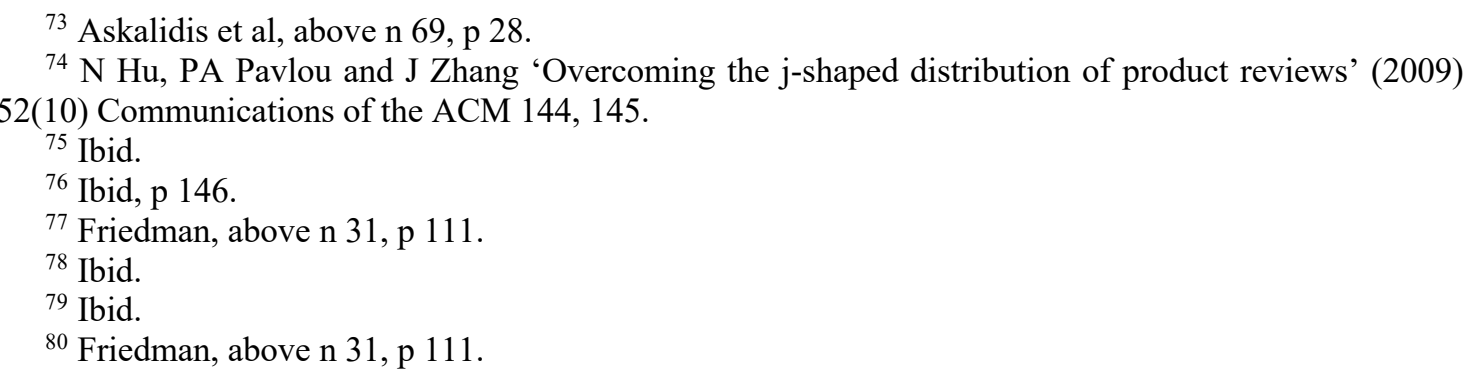


consumers while at the same time providing a worthwhile return for advertisers. ${ }^{81}$ Supportive platforms are less susceptible to such tension since they only constitute a part of a bigger platform. $^{82}$

The difficulty in balancing competing interests suggests that stand-alone platforms are susceptible to abuse. Suppliers can purchase a persuasive presence on such platforms and may pay for their products to be promoted first. ${ }^{83}$ Suppliers may pay for positive reviews to be highlighted, or for negative reviews to be censored, all of which can skew a consumer's assessment of a product. ${ }^{84}$ Instead of encountering unbiased CGRs, consumers will have to deal with information aimed at persuading rather than informing. Decisions induced by a deliberate redirection of information to fit advertising interests will likely yield sub-optimal outcomes..$^{85}$

A class-action suit against a US review website, Angie's List, highlights this problem. ${ }^{86}$ The complaint alleged that Angie's List concealed from consumers the fact that businesses could influence their ratings by paying to either appear higher in rankings or by suppressing unfavourable reviews. Where a business had paid advertising fees, negative reviews would not be counted when compiling ratings, and such reviews were made unreadable. ${ }^{87}$ Angie's List also allegedly altered its rankings by suppressing positive reviews unless a business paid for advertising. Angie's List denied that advertising revenue could affect ratings and stated that it disclosed receipt of revenue from businesses with high ratings. It, however, agreed that in

81 Ibid

${ }^{82}$ Friedman, above n 31, p 111.

${ }^{83}$ Ibid, p 103.

${ }^{84}$ Becher \& Zarsky, above n 50, pp 333-334.

${ }^{85}$ Friedman, above n 31, p 101.

${ }^{86}$ Moore v. Angie's List, Civil Action No. 15-1243. United States District Court, (E.D. Pennsylvania, August 7 2015) available at https://www.leagle.com/decision/infdco20150810c79

87 Ibid. 
certain situations, revenue accepted from businesses could affect the ranking of search results. Eventually, Angie's List agreed to settle the lawsuit by paying the settlement class.

Platform manipulation places consumers in a vulnerable position because they are given a false sense of empowerment in believing that they are making well-informed decisions when, in fact, their decisions are based on manipulated information. Decisions based on skewed information may not reflect consumers' preferences, thereby increasing the likelihood of detriment.

\section{b) Limited coverage}

Informed decision-making requires that consumers assess product features and price, as well as the terms on which they will contract. If consumers pay attention to contract terms and shop around for the most favourable ones, then suppliers will be incentivised to offer fair terms. ${ }^{88}$ Conversely, if consumers pay no attention to contract terms, then suppliers will reduce their costs and risks by offering one-sided terms. ${ }^{89}$ To combat this, one aspect of regulating contract terms requires their transparent disclosure, especially if they significantly impact a consumer's interest. ${ }^{90}$

Increased access to contract terms suggests that consumers will evaluate them before transacting. However, this is not always the case. Marrotta-Wurgler points out that consumers do not read the fine print and increased disclosures do not necessarily translate to increased engagement with contract terms. ${ }^{91}$ Some authors, however, contend that CGRs can contribute to solving this problem. For instance, Peppet argues that a consumer's review is likely to

\footnotetext{
88 F Marotta-Wurgler 'Does contract disclosure matter' (2012) available at https://www.law.columbia.edu/sites/default/files/microsites/contract-economicorganization/files/Marotta-Wurgler\%20paper.pdf p 2.

${ }^{89}$ Ibid.

${ }^{90}$ E.g. exclusion clauses. See the approach under the EU's Unfair Contracts Term Directive 93/13/EEC.

${ }^{91}$ Marotta-Wurgler (above n 88) p 3.
} 
evaluate a product based on multiple variables, one of which is the consumer's experience with the supplier's contract terms. ${ }^{92}$ Becher and Zarsky reason that consumers who encounter negative reviews about a supplier's terms will pay attention to the contract terms when deciding to transact. ${ }^{93}$ Therefore, ex-ante consumers will benefit from reviews provided by ex-post consumers who have experienced the contract terms. ${ }^{94}$

While these arguments have merit, certain matters must be considered before concluding that CGRs can assist with information on contract terms. First, CGRs will only be a useful source of information on contract terms if there are actual opinions on contract terms. ${ }^{95}$ Unlike mandatory disclosure where regulation dictates content, CGRs cover several issues, the scope of which is determined by the reviewer. CGRs may focus on a range of issues, and there is no obligation to discuss contract terms. Hence, CGRs may provide no information on contract terms. ${ }^{96}$

Second, Becher and Zarsky appear to assume that a sufficient number of ex-post consumers can understand contract terms, identify unfair ones and write reviews detailing their experiences with such terms. They also seem to assume that ex-ante consumers will easily identify such reviews and act on them. Since literature confirms that few consumers read disclosures about contract terms, it means that only a small pool of consumers can write reviews assessing them. ${ }^{97}$ Even when the terms are read, consumers may not give them considerable weight in their assessment of a product on balance with other features. ${ }^{98}$

\footnotetext{
92 SR Peppet 'Freedom of contract in an augmented reality: the case of consumer contracts' (2012) 59 UCLA L Rev 676, 726.

${ }^{93}$ Becher and Zarsky, above n 50, pp 352-353.

${ }^{94}$ Ibid, p 355.

${ }^{95}$ F Marotta-Wurgler 'Even more than you wanted to know about the failures of disclosure' (2015) 11 Jrslm Rev Legal Stud 63, pp 71-72.

${ }^{96} \mathrm{R}$ Van Loo 'The rise of the digital regulator' (2017) 66 Duke LJ 1267, p 1289.

${ }^{97}$ Ibid, p 72.

${ }^{98}$ NV Chari 'Disciplining standard form contract terms through online information flows: an empirical study’ (2010) 85 NYU L Rev 1618, 1645.
} 
Becher and Zarsky's argument is questioned by empirical research suggesting that reviews are unlikely to serve as an effective conduit for passing information on contract terms because many consumers do not take contract bias ${ }^{99}$ into account when writing reviews. ${ }^{100}$ Chari found that highly-rated products on Amazon often have pro-seller terms and that although reviews may contain information on contract terms, they are not conveyed in a way that is useful to ex-ante consumers. ${ }^{101}$

Ex-post consumers may not write about their experiences with contract terms unless they have suffered a negative experience linked to the enforcement of such term. ${ }^{102}$ If a negative experience never occurs, it is unlikely that such terms will be addressed in a CGR. Even where consumers have negative experiences, suppliers can adopt mechanisms to discourage them from posting reviews that draw attention to such terms. ${ }^{103}$ These mechanisms could include prompt dispute settlement or voluntary forbearance of contractual rights in the form of refunds and exchanges. If this is the case, CGRs may not discuss the unfair term. Even if a review discusses a dispute arising from a term's application but reports prompt resolution, other consumers may discount the unfavourable term as they may believe that a similar approach (prompt and favourable resolution) will be extended to them even though this is not guaranteed.

In other instances, CGRs on contract terms may not be presented in an explicit manner that is useful to ex-ante consumers. As stated earlier, since consumers do not often read contract term disclosures, they will usually experience controversial terms accidentally when a dispute concerning its application arises. ${ }^{104}$ Many consumers view such disputes in the abstract and are cannot link them to contractual provisions. ${ }^{105}$ Hence, a review may describe a trader's customer

\footnotetext{
99 "Bias" means the extent to which contract terms favour buyers or sellers. Ibid, p 1621.

100 Chari above n 98, p 1645.

101 Ibid, p 1618.

102 Becher and Zarsky, above n 50, p 315.

${ }^{103}$ Ibid, p 318.

${ }^{104}$ Ibid, p 315.

105 Ibid.
} 
service as lousy/inflexible when the actual source of their discontent is the application of a contract term. ${ }^{106}$ Such a review may not point out the problematic term(s) and, therefore, cannot place an ex-ante consumer in a position to make adjustments in response to such terms.

As noted earlier, CGRs may be textual or indicated by a review score. While textual reviews will be more useful for providing information on contract terms, review scores only reveal the overall perception of a product. As consumer preferences differ, they will apportion weight inconsistently to different factors/product features when arriving at a score. If ex-ante consumers cannot identify the extent to which reviews are based on the quality of contract terms, then such reviews are difficult to use as a proxy of contract term quality. ${ }^{107}$

Many consumer transactions are based on standard form contracts (SFCs). Terms contained in SFCs are frequently updated to adapt to market, regulatory and technological developments. ${ }^{108}$ If CGRs were to contain relevant assessments of an SFCs' terms, their effect might be negated by these frequent changes. This is because these changes can render the information flow irrelevant since reviews provided by ex-post consumers on outdated terms will be unhelpful to ex-ante consumers. ${ }^{109}$ The way reviews are compiled can also exacerbate this problem. If platform operators do not set time frames for removing obsolete reviews, there is a likelihood that reviews covering SFCs that have since been updated will continue to influence consumer decision-making. Where CGRs discuss outdated terms, the information they provide will be inconsequential or misleading.

The relevance of CGRs discussing contract terms may also be negated if contract term discrimination exists. Contract term discrimination covers ex-ante discrimination, where a

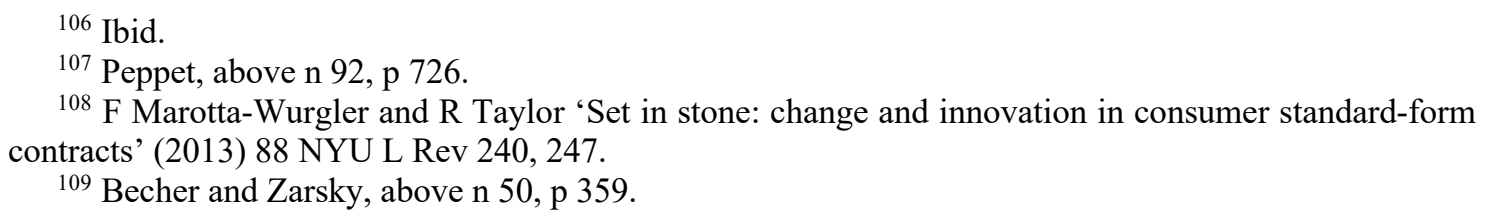

${ }^{108} \mathrm{~F}$ Marotta-Wurgler and R Taylor 'Set in stone: change and innovation in consumer standard-form contracts' (2013) 88 NYU L Rev 240, 247.

${ }^{109}$ Becher and Zarsky, above n 50, p 359. 
seller offers different terms to different consumers at contract formation. ${ }^{110}$ It also includes expost discrimination where in resolving disputes, sophisticated or assertive consumers obtain remedies that are not available to other consumers. ${ }^{111}$ If consumers purchasing the same product are subject to different terms, this can distort the flow of reliable information. In such situations, CGRs containing information on contract terms may not be accurately representative. ${ }^{112}$

\section{c) Not suitable for all types of goods}

Goods are sometimes classified based on how easily consumers can acquire and evaluate information about them before purchase. To this end, goods can be classified as search, experience, or credence goods. ${ }^{113}$ Search goods are defined as those whose attributes can be observed and verified before purchase. ${ }^{114}$ Experience goods are those whose quality can only be known after use while credence goods are those whose quality cannot be determined or verified even after purchase and use. ${ }^{115}$

When consumers purchase search goods in a brick and mortar setting, the information contained in CGRs will only serve to reinforce or confirm judgments held about a product since

${ }^{110}$ Ibid, p 309.

${ }^{111}$ Ibid.

${ }^{112}$ Ibid.

${ }^{113}$ P Nelson 'Information and consumer behaviour' (1970) 78(2) JPE 331; MR Darby and E Karni 'Free competition and optimal amount of fraud' (1973) 16 JLE 67.

${ }^{114}$ OECD Consumer Policy Toolkit (2010) available at https://doi.org/10.1787/9789264079663-en $\mathrm{p}$ 34.

${ }^{115}$ Ibid, p 35 .

Consumer-generated reviews: time for closer scrutiny? 
the quality is observable before purchase. ${ }^{116}$ In online environments, detailed descriptive CGRs can take on a more prominent role in confirming the product's search attributes. ${ }^{117}$

Information asymmetry problems are more pronounced in transactions involving experience and credence goods because consumers cannot verify their quality before purchase. ${ }^{118}$ One concern linked to this information asymmetry is that in situations where it is impossible to establish a good's quality in advance, consumers will only be prepared to pay an average price corresponding to the average expected quality. Sellers of high-quality goods will be unwilling to sell at that asking price and will withdraw from the market. The result is that the product quality will decline as will the price consumers are willing to pay. ${ }^{119}$ Reducing information asymmetry is, therefore, necessary to avoid such market failure.

While disclosures from suppliers may mitigate this problem, concerns remain that the nature of experience and credence goods make disclosures inadequate in reducing pre-purchase uncertainties. ${ }^{120}$ Since CGRs detail consumer experiences with products, one can assume that they will be more useful to ex-ante consumers purchasing experience and credence goods. ${ }^{121}$ In these cases, consumers often attach a higher weight to reviewer agreement than the actual

\footnotetext{
${ }^{116}$ W Tsao and M Hsieh 'eWOM persuasiveness: do eWOM platforms and product type matter' (2015) 15(4) ECR, 509, 519.

${ }^{117}$ Y Wan, M Nakayama and J Qin 'A test of search-experience-credence framework through online review' (2018) available

https://www.researchgate.net/profile/Makoto_Nakayama3/publication/328415093 Testing_SECframework through online review A Test of Search-Experience-

Credence Framework Through Online Review/links/5bcc92ae92851cae21b7b844/Testing-SECframework-through-online-review-A-Test-of-Search-Experience-Credence-Framework-Through-Online$\underline{\text { Review.pdf } \mathrm{p} 2 .}$

${ }^{118}$ L Pan and J Chiou 'How much can you trust online information? cues for perceived trustworthiness of consumer-generated online information’ (2011) 25 JIM 67, pp 69-70.

119 George Akerlof identified this phenomenon (Market for lemons) in his article 'The market for "lemons": quality uncertainty and the market mechanism' (1970) 84(3) QJE 488.

${ }^{120} \mathrm{G}$ Lewis 'Asymmetric Information, Adverse Selection and Online Disclosure: The case of eBay motors' (2011) 101 Am. Econ. Rev, 1535; H Hong, D Xua and GA Wang et al 'Understanding the determinants of online review helpfulness: a meta-analytic investigation' (2017) 102 DSS 1, 4.

${ }^{121} \mathrm{~S}$ Senecal and J Nantel 'The influence of online product recommendations on consumer online choices' (2004) 80 J. Retail 159,160.
} 
information contained in reviews. ${ }^{122}$ This means that consumers assess the credibility of the information in a review by observing the degree to which other reviewers agree on the quality of the product being reviewed. ${ }^{123}$

Peppet, therefore, reasons that if sufficient reviews about experience and credence goods are aggregated, then such goods can transform into search goods which are easily evaluated before purchase. ${ }^{124}$ Peppet's argument may find merit with experience goods. Since the quality of experience goods can be evaluated after purchase, consistent reviewer agreement on certain qualities may indicate a product's suitability. However, Peppet appears to assume that information contained in CGRs are a fool-proof indication of product quality. This assumption poses certain problems. First, the quality evaluations of many experience and credence products are subjective and dependent on user experience. ${ }^{125}$ Consumer preferences differ, and so their perception of quality will reflect this, which will, in turn, influence how they evaluate products.

Furthermore, products are often complex and, one product may possess different attributes simultaneously. ${ }^{126}$ A product may possess search, experience and credence attributes all at once. ${ }^{127}$ Reviews of such products can provide unintentionally misleading information. This is because consumers will attach varying levels of importance to the different attributes, and their reviews may not indicate this. ${ }^{128}$ Even where consumers can appreciate the complexity of a product's attributes, they may value the wrong features in the short term. This

\footnotetext{
${ }^{122}$ FR Jiménez, NA Mendoza 'Too popular to ignore: the influence of online reviews on purchase intentions of search and experience products' (2013) 27(3) JIM 226, 231.

${ }^{123}$ Ibid.

124 Peppet, above n 92, p 714.

$125 \mathrm{~S}$ Sen and D Lerman 'Why are you telling me this? An examination into negative consumer reviews on the Web' (2007) 21(4) JIM 76-94.

${ }^{126} \mathrm{Li} \&$ Hitt above n 53, p 7.

${ }^{127}$ Ibid; Y Wan, M Nakayama and N Sutcliffe 'The impact of age and shopping experiences on the classification of search, experience, and credence goods in online shopping' (2012) 10(1) Information Systems and e-Business Management 135, 138.

128 Ibid.
} 
is because owing to cognitive limitations, consumers do not always weigh the present and future costs and benefits of a decision and can be myopic in the short term. ${ }^{129}$

Moreover, for CGRs to provide a credible proxy for product quality, they must communicate the actual average quality of the product being reviewed. ${ }^{130}$ This is only possible if available CGRs are representative of the consumer population. ${ }^{131}$ As mentioned previously, consumers self-select to write reviews making it difficult to meet this requirement. ${ }^{132}$ Reviews are usually written by extremely satisfied or dissatisfied consumers who do not represent the average consumer's experience. ${ }^{133}$

Li and Hitt's empirical study of the book market is instructive. ${ }^{134}$ A book's author can be inspected before purchase and qualifies as a search attribute while the content can only be evaluated after reading, thereby qualifying as an experience attribute. ${ }^{135}$ Consumers attracted to the search attributes (an author's fans) will likely buy the author's book early and will rate the book highly in comparison to the rest of the population. ${ }^{136}$ Their reviews though truthful, will not be representative of all consumers.

With credence goods, the situation is more complicated. Empirical evidence suggests that most CGRs focus on discussing consumer experiences with search and experience goods. ${ }^{137}$ This is unsurprising because it is difficult to evaluate the quality of credence products after use. Hence, consumers may be cautious about reviewing such products. ${ }^{138}$ Moreover, because a product's search and experience attributes are easier to evaluate, consumers are more

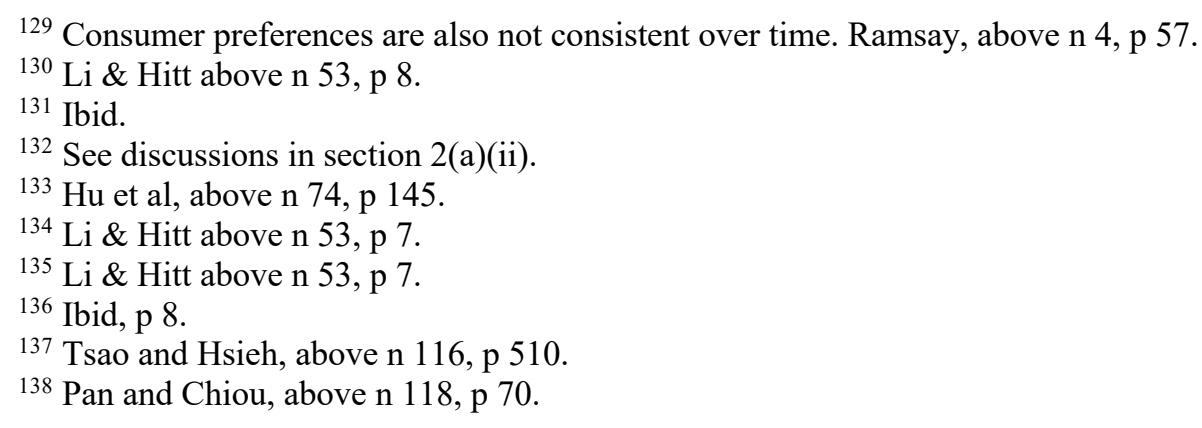


likely to write reviews in the early stage of a product's lifecycle. ${ }^{139}$ The difficulty with assessing credence goods means that consumers will spend more time evaluating them before they write reviews ${ }^{140}$ (if they eventually write one).

Even where reviews of credence goods are available, they may be an unreliable source of information on product quality or suitability. This is because many complex credence goods, like financial products, are often tailored to the specific circumstances of consumers. For instance, a mortgage plan is tailored to a consumer's financial status, and what is suitable for one may be unsuitable for another. The credence nature of a mortgage plan also means that the precise value of the product may never be known. Owing to these complexities, CGRs of such products often focus on ancillary issues. For instance, a financial product's reviews may comment on a bank representative's professionalism, the ambience of a branch or the waiting time. While this is helpful information, it does not provide a clearer assessment of the product's quality or suitability.

\section{d) Cognitive limitations}

As indicated in the introduction, one reason cited for the failure of mandatory disclosure is that it relies on the neo-classical assumption that consumers are rational and are the best judges of their interests who maximise their utility with the limited resources available. ${ }^{141}$ In reality, consumers are not unboundedly rational, and this is exhibited by judgment errors and deviations from the precepts of expected utility theory. ${ }^{142}$ Judgment errors are often linked to the limitations associated with the human capacity to process information. When faced with

\footnotetext{
${ }^{139}$ Wan et al, above n 117 , p 3.

140 Ibid.

${ }^{141}$ Ramsay above n 9 p 47.

${ }^{142}$ C Jolls and CR Sunstein 'Debiasing through law' (2006) 35 JLS 199, 203.
} 
too much information, consumers rely on mental shortcuts to justify their decisions. ${ }^{143}$ Reliance on these shortcuts can lead to cognitive biases. ${ }^{144}$

As stated earlier, Ben-Shahar and Schneider assert that when making unfamiliar decisions, consumers prefer advice such as reviews. ${ }^{145}$ They appear to assume that consumers are cognitively better-equipped to process information acquired through advice. This assumption cannot stand because consumer rationality remains limited, notwithstanding the information source. Information contained in CGRs, like any other information, is subject to the limitations of human information processing. ${ }^{146}$ Thus, cognitive biases can also affect how consumers process CGRs.

When deciding whether to purchase a product, consumers will often have access to a large pool of reviews. ${ }^{147}$ For instance, at the time of writing, consumers wishing to buy a set of TaoTronics wireless Bluetooth headphones on Amazon will have access to about 18,350 reviews. ${ }^{148}$ While this provides consumers with multiple perspectives, the large volume can lead to information overload. Assessing these reviews will be daunting because consumers must go through multiple reviews to decide which is credible and relevant. ${ }^{149}$

As stated earlier, information overload will force consumers to settle on mental shortcuts which can lead to cognitive biases. For example, consumers will be prone to the bandwagon effect when decision-making relies on CGRs. The bandwagon effect indicates that people are more likely to make a choice that is popular amongst an existing majority. ${ }^{150}$ Platforms

\footnotetext{
${ }^{143}$ KB Schulz 'Information flooding' (2015) 48 ILR. 755,759.

144 Jolls and Sunstein, above n 142, p 204.

${ }^{145}$ See introduction.

${ }^{146}$ MJ Thomas, B Wirtz, JC Weyerer 'Determinants of online review credibility and its impact on consumers' purchase intention' (2019) 20(1) JECR 1, 3.

${ }^{147}$ Gottschalk and Mafael, above n 25, p 89.

${ }^{148} \mathrm{https}: / /$ www.amazon.co.uk/Headphones-TaoTronics-Travelling-Waterproof-CancellingBlack/dp/B017I9CBPC/ref=sr 1 3?crid=1P657LMQZAG8Q\&keywords=bluetooth+headphones\&qid=1 $\underline{562862893 \& \mathrm{~s}=\text { gateway } \& \text { sprefix }=\text { bluet } \% 2 \mathrm{Caps} \% 2 \mathrm{C} 170 \& \mathrm{sr}=8-3}$

${ }^{149}$ Jiménez and Mendoza, above n 122, p 234.

$150 \mathrm{R}$ Schmitt-Beck 'Bandwagon effect' in G Mazzoleni (ed) The International Encyclopedia of Political Communication. Volume 1 (Chichester: John Wiley \& Sons, $1^{\text {st }}$ edn, 2016) p 56.
} 
incorporate mechanisms that allow consumers to signal agreement with a review. For instance, Amazon allows consumers to indicate if a review is helpful. This generates statistical information on the number of consumers endorsing a review. ${ }^{151}$ These endorsement mechanisms affect the perception of particular reviews and can induce a bandwagon effect. ${ }^{152}$ Consumers may process such mechanisms as heuristic cues for evaluating the credibility of information supplied. ${ }^{153}$

The level of reviewer agreement can also trigger the bandwagon heuristic. One study indicates that consumers may purchase a product because most reviews agree on the quality of certain attributes which they consider important. ${ }^{154}$ Focusing on the online purchase of books, another study confirms this. ${ }^{155}$ Results showed that consumers rely on the sales volume and star ratings of a book to evaluate its quality. ${ }^{156} \mathrm{~A}$ high sales volume or star rating indicates a products' popularity. Basing a decision on these indicators can be tricky because the reviewers may not be a truly representative class, and the information signals about quality may not be accurate.

Consumers may also be subject to confirmation bias when processing information in CGRs. They may justify their decisions by latching onto particular CGRs which confirm their preconceived notions of a product. ${ }^{157}$ Consumers tend to perceive CGRs that confirm their initial impression of a product as more helpful. ${ }^{158}$ Since the initial impression may be influenced by the average rating of the product, one consequence of confirmation bias is that

${ }^{151} \mathrm{~T}$ Wu and CA Lin 'Predicting the effects of eWOM and Online Brand Messaging: Source Trust, Bandwagon effect and Innovation Adoption Factors' (2017) 34 Telematics and Informatics 470, 473.

152 Ibid.

153 Ibid.

154 Jiménez and Mendoza, above n 122, p 233.

${ }^{155}$ F Chen 'Herd behavior in purchasing books online' (2008) 24(5) Computers in Human Behavior 1977.

${ }^{156}$ Ibid, pp 1984-1985.

${ }^{157}$ Friedman, above n 31, p 595.

${ }^{158} \mathrm{D}$ Yin, S Mitra, H Zhang 'When do consumers value positive vs. negative reviews? an empirical investigation of confirmation bias in online word of mouth' (2016) 27(1) ISR 131. 
the perceived helpfulness of a review is dependent on a product's average rating. ${ }^{159}$ If a product has high positive ratings with an average of five-stars, negative reviews are perceived as deviating from the average rating and will not be considered helpful. ${ }^{160}$ The opposite would apply to products with low ratings. Thus, consumers may disregard CGRs that contradict their initial perception of a product informed by its ratings.

When processing information, consumers may also be subject to the overconfidence bias. Consumers can be overconfident about their abilities and may believe that in carrying out an action, they will enjoy an outcome better than the average expected outcome. ${ }^{161}$ This will, for instance, cause consumers to overestimate their ability to navigate contract terms ${ }^{162}$ or to ignore generic warnings because they assume that a problem will not affect them. ${ }^{163}$ Peppet argues that online environments may neutralise consumers' overconfidence because 'reading online consumer reviews highlights the obvious but important fact that sheer volume of experience uncovers even very low-probability contingencies. ${ }^{164}$ This implies that CGRs will put consumers on notice about the occurrence of different outcomes, thus lessening the incidents of overconfident decisions. ${ }^{165}$

Although it is tempting to agree with this view, one must note that a consumer's optimism bias can erode the gains Peppet expects. Optimism bias refers to people's tendency to believe that the probability of them facing a bad outcome is lower than it actually is. ${ }^{166}$ Because CGRs are subjective, aggregated reviews can contain conflicting information that makes it challenging to decipher which is credible. ${ }^{167}$ Notwithstanding a significant number of

\footnotetext{
${ }^{159}$ Ibid, p 132.

${ }^{160}$ Ibid, p 134.

${ }^{161}$ OECD, above n 114 p 75; Sunstein \& Thaler, above n 10, p 32.

${ }^{162}$ D Grubb 'Overconfident consumers in the marketplace' (2015) 29(4) J Econ Perspect. 9, 9

${ }^{163}$ Ramsay above n 4, p 58.

${ }^{164}$ Peppet, above n 92, p 739.

165 Ibid, p 739; Becher and Zarsky, above n 50, p 355.

166 Jolls and Sunstein, above n 142, p 204.

${ }^{167}$ H Hong, D Xua and GA Wang et al 'Understanding the determinants of online review helpfulness: A meta-analytic investigation' (2017) 102 DSS 1, 1.
} 
complaints about a product, some exceptional positive experiences may lead consumers to expect that the latter will be their likely outcome. ${ }^{168}$ Thus, even with access to accurate information on possible contingencies, optimism bias may cause consumers to underestimate their personal risks. ${ }^{169}$

Tversky and Kahneman explain that there are situations in which people assess the probability of an event by the ease with which examples can be brought to mind. ${ }^{170}$ While this availability heuristic can be useful when assessing frequency or probability, it can also lead to bias. ${ }^{171}$ This bias can affect consumers relying on CGRs because they may use information from specific reviews as a heuristic for what the broader picture looks like. ${ }^{172}$ Hence the expected outcome of a transactional decision may be based on an easily recalled peer experience. ${ }^{173}$

Consumers may make decisions relying on any of these biases and may even express satisfaction with it, but there remains a possibility that they have forgone a superior transaction. ${ }^{174}$ With the susceptibility to these biases, one must question whether, in comparison to mandatory disclosures, consumers are better placed to process the information obtained from reviews. While CGRs may contribute towards providing consumers with information, they do not solve the problem associated with sub-optimal information processing. ${ }^{175}$

\footnotetext{
${ }^{168}$ Friedman, above n 31, p 128.

169 Jolls and Sunstein, above n 142, p 207.

${ }^{170}$ A Tversky and D Kahneman 'Judgment under uncertainty: heuristics and biases' (1974) 185 Science (New Series) 1124, 1127

${ }^{171}$ Ibid, p 1127.

${ }^{172}$ DA Friedman, 'Debiasing advertising: balancing risk, hope and social welfare' (2011) 19 JLP 539, 590

${ }^{173}$ Friedman, above n 31, p 128.

${ }^{174}$ Ibid, p 133

${ }^{175}$ Van Loo, above n 96, p 1276.
} 


\section{REGULATORY CONSIDERATIONS}

The challenge for regulators is to ensure that where possible, consumers make decisions based on fair information. Some of the issues raised in section two, such as bias, can be minimised through regulation. Resolving other problems linked with cognitive limitations will be trickier because of inherent human limitations. Nonetheless, since RPs play an intermediary role in facilitating the exchange of CGRs, this article takes the view that they should be at the centre of regulatory efforts addressing some of highlighted the issues. Accordingly, discussions in this section mainly focus on RPs and review platform operators (RPOs).

\section{a) Is regulatory intervention necessary?}

Some authors suggest that regulation may be unnecessary because RPOs have an incentive to prevent the abuse of RPs. ${ }^{176}$ Friedman explains that to keep RPs relevant, RPOs must attract, retain and engage consumers. ${ }^{177}$ If consumers suspect that a platform is compromised, they will disengage. The competition for users, therefore, inspires RPOs to develop self-regulatory mechanisms to compete on grounds of utility and credibility. ${ }^{178}$ Moreover, market-based solutions like litigation ${ }^{179}$ can keep RPOs and businesses in check and deter the abuse of RPs. ${ }^{180}$

\footnotetext{
${ }^{176}$ See Friedman, above n 31; E Goldman, 'The regulation of reputational information' in B Szorka \& A Marcus (eds) The Next Digital Decade: Essays on the Future of the Internet (Washington: TechFreedom, 2010) p 299.

${ }^{177}$ Friedman, above n 31, p 135.

178 Ibid.

179 This covers private civil actions instituted by consumers, direct litigation between businesses and class actions.

${ }^{180}$ Friedman above n 31, p 147-161.
} 
Friedman's argument is supported by evidence of voluntary self-regulatory efforts adopted by RPOs. For instance, Amazon allows verified purchaser badges on reviews which help to confirm reviewer authenticity. Google provides a right of reply, which enables businesses to respond to information contained in reviews. The RP offered by the UK's health and beauty retailer, Boots, indicates when reviews are written by a staff-customer, if reviews are part of a promotion and if reviewers received a free sample. This presumably allows consumers to decide how much they can trust the information supplied. Others allow users to mark reviews as suspicious or helpful and therefore put consumers on notice that a review may be unreliable or worth considering. ${ }^{181}$ Some RPs use software or sting operations to detect fake reviews. ${ }^{182}$ While commendable, these efforts are not consistent on every platform, are often non-binding, and no guarantee exists that most RPOs will uniformly adopt such measures. Moreover, as pointed out in section two, many RPOs face conflicts of interests which indicates that they cannot be trusted to engage neutrally in self-regulation.

Friedman's view is further problematic because it still rests on the assumption that consumers are rational and that upon detecting that a platform has left itself open to abuse, they will abandon it. As highlighted in section 2(d), consumer rationality is not always guaranteed. Second, important literature details the weaknesses of private law mechanisms such as litigation. ${ }^{183}$ Plagued with economic, organisational and procedural obstacles, litigation is not always a viable option for regulating economic behaviour. Third, Fink points out that isolated self-regulation lacks transparency and fails to take into account the interests of other

\footnotetext{
${ }^{181}$ Competition \& Markets Authority 'Online Reviews and Endorsements: Report on CMA's Call for (June 2015) available at https://assets.publishing.service.gov.uk/government/uploads/system/uploads/attachment data/file/43623

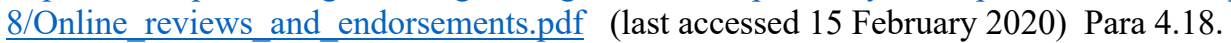

182 Yelp carried out sting operations to discourage businesses from soliciting fake reviews. https://www.nytimes.com/2012/10/18/technology/yelp-tries-to-halt-deceptive-reviews.html

${ }^{183} \mathrm{~S}$ Talesh 'How the "haves" come out ahead in the twenty-first century' (2013) 62 DLR 519; M Galanter 'Why the haves come out ahead: speculations on the limits of legal change' (1974) 9 Law \& Soc'y Rev 95; AA Leff 'Injury, ignorance and spite -the dynamics of coercive collection' (1970) 80 YLJ 1.
} 
stakeholders other than the platform. ${ }^{184}$ Hence, to safeguard public interests, external interference may be needed for a counterbalance. ${ }^{185}$ For these reasons, evidence of selfregulation should not sustain calls for regulatory non-intervention.

\section{b) Relying on existing regulatory frameworks}

One can argue that it is more practical to rely on existing frameworks in regulating some of the problems highlighted in section two. For instance, before the UK House of Lords' Select Committee on European Union, most witnesses believed that rather than introducing new regulations, the European Commission ought to focus on reviewing existing laws and their application to online platforms. ${ }^{186}$ In our context, current regulations, particularly those regulating unfair trading practices, may be of great relevance.

At EU level, the European Commission (the Commission) has made efforts to clarify the Unfair Commercial Practices Directive (UCPD)'s application to RPs. ${ }^{187}$ The revised Guidance on the implementation/application of the UCPD has a section dedicated to 'user review tools'. ${ }^{188}$ This section provides some insight into how the UCPD may apply. For instance, the Commission clarifies that since the UCPD applies to natural and legal persons who qualify as 'traders', it covers consumers who act on behalf of traders when posting reviews. Articles 6(1)(b) and 7(4)(a) requires that RPOs provide truthful information on the main characteristics of their services and therefore should not mislead consumers on the origin of reviews. ${ }^{189}$

\footnotetext{
${ }^{184}$ M Fink 'Digital co-regulation: designing a supranational legal framework for the platform economy' (2018) 43(1) ELR 47,56.

185 Ibid, p 57.

${ }^{186}$ House of Lords, Select Committee on European Union Online Platforms and the Digital Single Market (HL Paper 129) https://publications.parliament.uk/pa/ld201516/ldselect/ldeucom/129/129.pdf p 93.

187 Similar efforts were made earlier at national level: see the UK's CMA above n 181: Danish Consumer Ombudsman, 'Guidelines on Publication of User Reviews' (May 2015) available at https:/www.consumerombudsman.dk/media/49717/guidelines.pdf
188 See para 5.2.8, UCPD Guidance available
at https://eur-lex.europa.eu/legalcontent/EN/TXT/HTML/?uri=CELEX:52016SC0163\&from=EN

${ }^{189}$ Ibid.
} 
Platforms will engage in a misleading action contrary to Article 6 or a misleading omission contrary to Article 7 if they suppress reviews without notifying consumers that they are being presented with only selected reviews. ${ }^{190}$ This could also be a practice contrary to the requirements of professional diligence under Article 5(2). Connections between RPOs and traders must be disclosed if the connection could materially affect the credibility of reviews. ${ }^{191}$ Failing to do so would breach Article 6(1)(c) and 7(2). Fake endorsement of reviews (e.g. 'likes') also breaches Article 6. Where a trader posts fake reviews in the name of consumers, they will be acting contrary to point No 22 of Annex I of the UCPD which prohibits 'falsely representing oneself as a consumer.'192

Relying on the UCPD, however, raises some issues. Like most EU Directives with consumer protection themes, the UCPD is drafted in the context of bilateral transactions completed between two parties: the trader and consumer. ${ }^{193}$ The prohibitions in the UCPD focus on regulating the conduct of traders and will only apply if parties fall within the relevant definitions. CGRs introduce third party considerations which do not always fit with the Directive's party designations. The UCPD defines a trader to mean:

'any natural or legal person who, in commercial practices covered by this Directive, is acting for purposes relating to his trade, business, craft or profession and anyone acting in the name of or on behalf of a trader' ${ }^{\prime 194}$

Commercial practices cover:

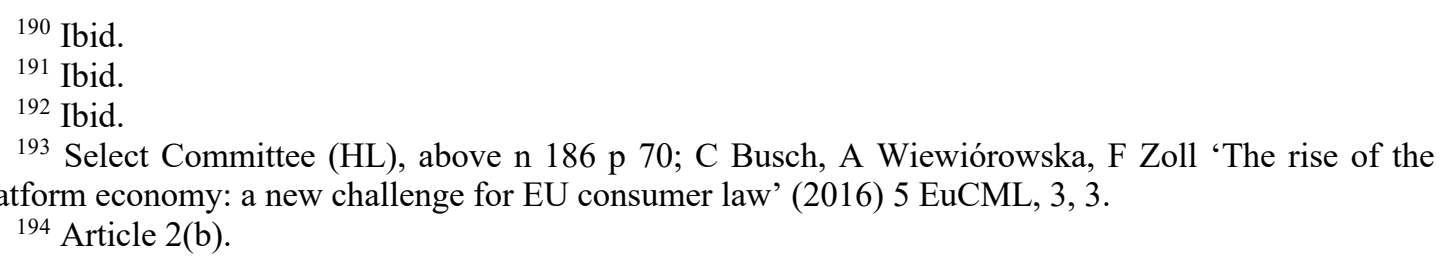


'any act, omission, course of conduct or representation, commercial communication including advertising and marketing, by a trader, directly connected with the promotion, sale or supply of a product to consumers' ${ }^{195}$

These definitions are broad and will capture online retailers incorporating RPs (supportive platforms). However, it is unclear if stand-alone platforms which only provide a forum for posting reviews, without more, can qualify as a trader. Stand-alone RPs which do not offer advertising services may not qualify as engaging in a commercial practice. EU case law suggests that the concept of trader is defined by reference to the trader's commercial activity and that the UCPD extends only to commercial practices directly connected with the promotion, sale or supply of a product to consumers. ${ }^{196}$ Applying this, it may be challenging to show that simply providing an RP establishes a direct connection to the supply of products and services unless an argument is made that the information supplied qualifies as a product. ${ }^{197}$ Therefore, the current definitions of trader and consumer may require revision to capture transactions falling outside the traditionally defined trader-consumer relationships. ${ }^{198}$

Currently, it appears that the UCPD will only be useful in some situations. First, the UCPD can be relied on where platforms qualifying as traders (or consumers acting on their behalf) are directly involved in practices breaching the Directive. Second, the UCPD will apply where platforms collude with traders in manipulating CGRs which mislead consumers (in such situations, RPOs will be seen to act on a trader's behalf). While this may cover many cases, situations falling outside these scenarios may be left outside the UCPD's reach.

\footnotetext{
195 Article 2(d).

${ }^{196}$ Case C-59/12, BKK Mobil Oil v Zentrale zur Bekämpfung unlauteren Wettbewerbs, October 3, 2013, para 35 .

${ }^{197}$ One can respond to this by arguing that consumers supply the information while platforms only provide a repository.

198 Written evidence from Citizens Advice (OPL0082) available at http://data.parliament.uk/writtenevidence/committeeevidence.svc/evidencedocument/eu-internal-marketsubcommittee/online-platforms-and-the-eu-digital-single-market/written/26136.html
} 
Another concern is that the UCPD may be ill-suited for regulating RPs, which continuously evolve due to changing technology. The Commission acknowledges that many practices highlighted in the UCPD's annex are designed for the offline world. ${ }^{199}$ This may suggest that the UCPD may be ill-equipped to address specific practices that only occur in online settings. Therefore, it seems that a regulatory instrument designed with the peculiarities of the online world in mind may be more appropriate.

\section{c) Designing a New Regulatory Landscape: Drawing Inspiration from Co-regulation} and Standardisation

The Commission has indicated that:

'where appropriate, self-regulation and co-regulation can often achieve better outcomes for enabling the development of strong platform ecosystems in Europe and can complement or reinforce the existing legislation that already governs certain activities of online platforms. ${ }^{200}$

As indicated in section 3(a), this paper takes the view that self-regulation will not be appropriate. Alternatively, co-regulation may present a suitable option for regulating RPs. Coregulation is a regulatory mechanism whereby:

"a Community legislative act entrusts the attainment of the objectives defined by the legislative authority to parties which are recognised in the field (such as

\footnotetext{
199 European Commission 'Impact assessment: proposal for a regulation of the European parliament and of the council on promoting fairness and transparency for business users of online intermediation services' available at https://ec.europa.eu/newsroom/dae/document.cfm?doc id=51797 para 5.4.3.

${ }^{200}$ Communication from the Commission on online platforms and the digital single market COM (2016) 288 final available at https://eur-lex.europa.eu/legalcontent/EN/TXT/HTML/?uri=CELEX:52016DC0288\&from=EN)
} 
economic operators, the social partners, non-governmental organisations, or associations). ${ }^{201}$

Essentially, with co-regulation, a regulator defines an objective in a binding legislative instrument while the implementation details are prepared by stakeholders in the regulated industry. Rather than a separate co-existence, co-regulation combines the use of legislation which is binding and predictable with self-regulatory mechanisms which are flexible in a single regulatory framework. ${ }^{202}$ This approach can promote efficiency since it frees up legislative capacity and ensures stakeholder involvement. ${ }^{203}$ It also promises a predictable legal framework while giving 'sufficient flexibility to industry to shape and decide on their voluntary commitments, respecting the speed of innovation'204

Co-regulatory efforts have been endorsed under the EU's 'new approach' to regulation. The 'new approach' involves the adoption of a legislative instrument which defines essential requirements concerning the regulation a matter of public interest and a harmonised standard which facilitates the compliance with the essential requirements. ${ }^{205}$ These standards are developed in an institutional setting that supports transparency and stakeholder participation. ${ }^{206}$ Where businesses adopt the harmonised standards, they benefit from a presumption of conformity with the essential requirements set in the legislation. ${ }^{207}$

\footnotetext{
201 Interinstitutional agreement on better law-making (2003/C 321/01) available at https://eurlex.europa.eu/legal-content/EN/TXT/HTML/?uri=CELEX:32003Q1231(01)\&from=EN para 18.

202 Opinion of the European Economic and Social Committee on "Simplification" (2002/ C 48/28) available content/EN/TXT/HTML/?uri=CELEX:52001AE1496\&from=EN)

https://eur-lex.europa.eu/legal-

${ }^{203}$ Opinion of the European Economic and Social Committee on self-regulation and co-regulation in the Community legislative framework (2015/ C 291/05) available at https://eur-lex.europa.eu/legalcontent/EN/TXT/HTML/?uri=CELEX:52014IE4850\&from=EN

204 above n 199, para 5.4.3.

205 The European Committee for Standardisation 'New approach and other directives' available at https://www.cen.eu/work/supportlegislation/directives/pages/default.aspx

${ }^{206} \mathrm{C}$ Busch 'Towards a new approach in European consumer law: standardisation and co-regulation in the digital single market' (2016) EuCML 197,198.

${ }^{207}$ CEN, above n 205.
} 
Busch argues that a harmonised regulatory framework for RPs can benefit from adopting this 'new approach' to regulation. ${ }^{208}$ Hence, Bush suggests that the regulation of RPs may be achieved through a Directive that defines the general regulatory principles combined with a European standard formulated by the European Committee for Standardization. ${ }^{209}$ The role of standardisation as a viable regulatory option has been endorsed by the International Standards Organisation, which in 2018 published the ISO 20488 ('the standard') applicable to online consumer reviews. ${ }^{210}$ The standard provides 'requirements and recommendations for the principles and methods for review administrators to apply to their collection, moderation and publication of reviews ${ }^{211}$ They apply to all organisations which publish reviews including suppliers who collect reviews from their customers and third-party platforms, whether independent of the supplier or not. ${ }^{212}$ Though non-binding, the standard provides an international template for further concrete regulatory efforts in the area.

\section{i. IMPOSING A HARMONISED DUTY OF CARE}

Growing evidence suggests that regulators will demand more accountability from RPOs in the near future. For instance, the Commission acknowledges that in respect of access to information and content for many parts of society, platforms are increasingly taking centre stage. This role, necessarily, brings with it a wider responsibility. ${ }^{213}$ In jurisdictions like the UK, there are discussions about imposing a duty of care on platforms to prevent online

\footnotetext{
208 Busch 'Towards a New approach in European consumer law' above n 206, p 197; C Busch, 'Crowdsourcing Consumer Confidence: how to regulate online rating and review systems in the collaborative economy' (June 15, 2016). Available at: http://dx.doi.org/10.2139/ssrn.2799489 p 14.

${ }_{209}$ Busch 'Crowdsourcing consumer confidence' above n 208, p 8.

${ }^{210} \mathrm{https://www.sis.se/api/document/preview/80004556/}$

${ }^{211}$ Para 1 ISO 20488:2018.

${ }^{212}$ Ibid.

213 https://eur-lex.europa.eu/legal-content/EN/TXT/HTML/?uri=CELEX:52016DC0288\&from=EN para $4.10(\mathrm{e})$.
} 
harms. ${ }^{214}$ The UK's Competition and Market's Authority recognises that online platforms should supervise their users and ensure they can comply with consumer protection law. ${ }^{215}$ The ISO standards also acknowledge that RPOs should adopt best practices.

Accordingly, this paper proposes a new regulatory framework that imposes a duty of care on RPOs. This duty of care will require that RPOs reasonably ensure that mechanisms are put in place to discourage the abuse of RPs. Broadly drafted, such duty will apply to all RPOs who provide a forum accessible to consumers located in the EU for the sharing and publication of reviews. ${ }^{216}$ The duty will be owed to all platform users located in the EU and will cover consumers whose transactional decisions may be affected by the abuse of RPs.

As the intermediaries central to the information exchange facilitated through CGRs, RPOs wield significant influence. As seen in section 2(a)(iii), they control the platforms and can re-engineer information by highlighting or suppressing positive/negative CGRs. Hence, it is justifiable that obligations are imposed on them to support the provision of fair information.

\section{ii. HOW WILL THE PROPOSAL WORK?}

Owing to the cross-border reach of RPs, regulatory efforts at EU level will be more appropriate as this will provide a coherent and harmonised approach to regulation. Fragmented national regimes $^{217}$ will create uncertainty and confusion for consumers and businesses, and this will, in turn, create barriers in the European Single Market. ${ }^{218}$

\footnotetext{
214 https://www.gov.uk/government/consultations/online-harms-white-paper/online-harms-whitepaper

15 Select Committee (HoL) above n 186, p 71.

${ }^{216}$ Which include supportive and stand-alone operators, regardless of where they are established. As this proposal focuses on consumer protection, it seems inappropriate to apply thresholds exempting specific platforms from the duty.

${ }^{217}$ E.g. see France's Digital Republic Act (French Act No. 2016-1321) and Law N. 1321 (Loi pour une République numérique of October 7,2016) which introduce regulations applying to online platforms; Germany's Network Enforcement Act (NetzDG) 2017 which regulates online social media platforms.

${ }^{218}$ Busch 'Crowdsourcing consumer confidence' above n 208, p 2.
} 
Building on Busch's suggestion, the proposed regime will adopt a co-regulatory approach. Hence, to avoid a disproportionate response, a legislative instrument can define the scope and essential elements of the duty of care while guidelines and industry codes can elaborate on how RPOs may meet the duty.

Instead of a Directive as suggested by Busch, this paper proposes the use of a Regulation as the legislative instrument of choice. This is for several reasons. First, it addresses concerns about regulatory coherence in the Single Market since Regulations introduce mandatory rules at Union level. ${ }^{219}$ Second, a Regulation will not be subject to transposition delays associated with Directives. This will promote certainty, which results from the uniform and immediate application of adopted rules. Third, it conforms with recent regulatory initiatives in the EU focusing on online platforms. For instance, to promote fairness and transparency for business users of online platforms, the EU's instrument of choice was a Regulation (i.e. the Online Platform Regulation). ${ }^{220}$

To clarify how RPOs may meet the duty of care, the Commission can develop guidelines which endorse the ISO standard. ${ }^{221}$ In line with co-regulatory principles, it can also encourage and endorse industry codes of practice. An RPO can demonstrate that it has met its duty of care if it conforms with standards/codes of practice developed by industry.

Such industry codes may build on the ISO standards in articulating more specific measures for meeting the duty of care. The ISO standards require that RPOs take certain principles into account when planning, designing and delivering RPs. These principles include

\footnotetext{
${ }^{219}$ For a discussion on the use of regulations in EU consumer law, see C Twigg-Flesner 'Good-bye harmonisation by directives, hello cross-border only regulation?' - a way forward for EU consumer contract law (2011) 7(2) ERCL 235.

${ }^{220}$ Regulation (EU) 2019/1150.

${ }^{221}$ Along with guidelines to be issued by the European Commission, the Online Platform Regulation encourages industry participants to draw up codes of conduct which support compliance with the regulatory requirements: Article 17.
} 
integrity, accuracy, privacy, security, transparency, accessibility and responsiveness. ${ }^{222}$ These principles reflect common themes in existing regulatory efforts and academic work in the area. ${ }^{223}$ These themes cover the collection, processing, moderation and publication of reviews. It also includes matters relating to transparency in the use of consolidated reviews and the disclosure of existing commercial relationships. The common themes suggest that convergence is occurring, and the proposed intervention will provide a framework for codifying these developments.

The advantages of this approach are manifold. First, these efforts can place RPOs in a position to reduce some of the problems identified in section two. For instance, requiring that RPOs adopt best practices in processing reviews can address the prevalence of fake reviews. Reliance on misleading information may be reduced if RPOs are required to disclose paid reviews and commercial relationships with businesses. Time limits imposed on the visibility of published reviews can address concerns about consumers relying on outdated reviews where, for instance, terms and conditions have changed. Requiring that RPOs include prominent notices advising consumers to consider contract terms along with CGRs may nudge consumers to review the fine print.

Second, a broadly drafted duty of care whose implementation is supported by industry codes allows for future-proofing. Rapidly changing technology will affect how RPs evolve, and an overly prescriptive framework will be ineffective. Industry codes are flexible and can be regularly updated to reflect changing technology and consumer behaviour. Third, a duty of care focuses on an objective - in this context, preventing the abuse of RPs - and leaves the

\footnotetext{
222 Para 4.1

${ }^{223}$ The work carried out by the French national organisation for standardisation: Association Française de Normalisation (AFNOR) influenced these standards. Other influential efforts include the Danish Guidelines, above n 208; The UK CMA's report, above n 201; The Draft Directive on Online intermediary Platforms developed by the Research Group on the law of digital services under the umbrella of the European Law Institute available at https://www.elsi.uniosnabrueck.de/fileadmin/user_upload/English.pdf
} 
detail of the means to those best placed to come up with solutions. ${ }^{224}$ This fits with the coregulatory approach favoured by the EU. Fourth, a duty of care does not exclude the possibility of other measures and can provide a foundation for more detailed interventions to target specific circumstances. ${ }^{25}$ Finally, industry efforts which are designed within a binding regulatory framework overseen by external regulators are more likely to engender consumer trust.

\section{iii. COMPATIBILITY WITH EXISTING LIABILITY REGIMES}

The current liability regime applying to online platforms is set under the E-commerce Directive (ECD). ${ }^{226}$ The ECD harmonises limitations on liability for online intermediaries that provide caching $^{227}$ or hosting services ${ }^{228}$ or which act as a mere conduit of information. ${ }^{229}$ Relevant to our discussion is the fact that online platforms will not be liable for any illegal content hosted (or stored) on their platform if they are not aware of such information and if upon obtaining knowledge, they act expeditiously in removing or disabling access to such information. ${ }^{230}$

The liability exemptions cover civil, criminal and administrative liability regarding all illegal activities initiated by third parties online, including unfair commercial practices and misleading advertising. ${ }^{231}$ In our context, this means that RPOs will benefit from the existing exemptions and will not be liable for (potentially) defamatory or false third-party reviews. EU

\footnotetext{
${ }^{224}$ LWoods and W Perrin 'Online harm reduction - a statutory duty of care and regulator' (April 2019) available at https://d1ssu070pg2v9i.cloudfront.net/pex/carnegie uk trust/2019/04/08091652/Onlineharm-reduction-a-statutory-duty-of-care-and-regulator.pdf p 28.

${ }^{225}$ Ibid, p 8.

${ }^{226}$ Directive 2000/31/EC.

227 Article 13.

${ }^{228}$ Article 14.

${ }^{229}$ Article 12.

${ }^{230}$ Articles 14(1)(a) \& (b). In other jurisdictions like the United States, online platforms also enjoy liability exemptions for third-party content: see 47 U.S.C. $\$ 230$ (2012).

${ }^{231}$ L Rozenfeldova and P Sokol 'Liability regime of online platforms new approaches and perspectives' (2019) 3 ECLIC 866, 870.
} 
case law supports this conclusion. For instance, Busch et al report that in 2015 , in an action brought by a hotel business against a hotel review site operator, a German federal court held that the operator was not liable for a third-party review which suggested that the hotel had bedbugs. $^{232}$

One pressing question is how the proposed framework in this paper will fit with the ECD's liability regime. It is argued that the proposal is not incompatible with the ECD's regime for several reasons. First, recital 48 of the ECD states that the Directive:

'does not affect the possibility for Member States of requiring service providers, who host information provided by recipients of their service, to apply duties of care, which can reasonably be expected from them and which are specified by national law, in order to detect and prevent certain types of illegal activities.'

This suggests that the ECD permits other forms of liability arising from imposed duties of care as long as they are not incompatible with the exemptions in the Directive. Second, the ECD emphasises that Member States should not impose a general obligation on internet intermediaries to monitor information which they transmit or store neither should there be an obligation to actively seek out facts or circumstances indicating illegality. ${ }^{233}$ The proposal complies with this because RPOs are not required to police review content or to ensure absolute veracity. Instead, it encourages RPOs to adopt pro-active measures which minimise the abuse of RPs.

\section{CONCLUSION}

232 BGH, 19.03.2015, MMR 2015, 726 - Hotelbewertungsportal cited in Busch 'Crowdsourcing consumer confidence', above n 229, p 11.

${ }^{233}$ Article 15. 
Informed decision-making is crucial to protecting the interest of consumers. Traditionally, consumers have mainly relied on information emanating from businesses to bridge information gaps. However, with the growth of the internet, consumers increasingly rely on other sources of information such as CGRs. CGRs affect consumer decision-making and therefore warrant closer inquiry. This paper has focused on highlighting the problems associated with CGRs which justify regulatory scrutiny. The paper has also laid out possible regulatory responses to some of these problems. Owing to their role as communication intermediaries, this paper suggests that RPOs are central to regulatory efforts aimed at minimising the abuse of review platforms. 